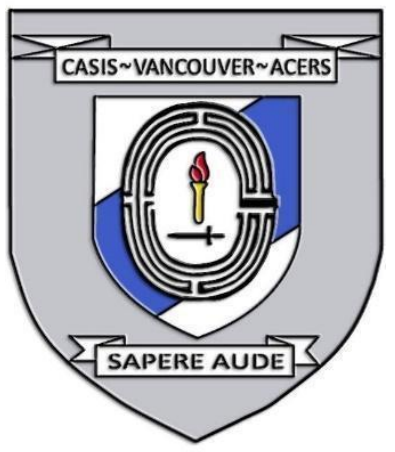

\title{
HOW POLICING HAS CHANGED SINCE COVID-19
}

Date: November $26^{\text {th }}, 2020$

Disclaimer: This briefing note contains the encapsulation of views presented by the speaker and does not exclusively represent the views of the Canadian Association for Security and Intelligence

\section{KEY EVENTS}

Superintendent Asif Rashid of Calgary Police discussed policing changes since COVID-19 on November 26, 2020 at the 2020 CASIS West Coast Security Conference. The presentation was followed by a question and answer period with the other speakers of the panel. The key points discussed were how policing was changed to adapt to the challenges of COVID-19, emergency management systems, and technological issues.

\section{NATURE OF DISCUSSION}

\section{Presentation}

Superintendent Rashid raised the issues of managing an overwhelming influx of information, continuity plans for a problem that does not seem to have a definite end (COVID-19), and changes in types and number of crimes. Superintendent Rashid also presented on the issues law enforcement staff faced with community policing, management, and mental health.

\section{Question Period}

The question period focused on mental health issues people faced, misinformation, and law enforcement responsibilities.

\section{BACKGROUND}

\section{Presentation}

Superintendent Rashid compared the overwhelming trickle of information influx to a tsunami within the Calgary Police, which was unlike other policing emergencies where a sudden onset had a definitive end. There was an awareness of COVID-19, but preparations for the pace, change of information, and public health orders were non-existent. The budget shortfalls raised problems for the 
maintenance of service to the community, which was deemed important. To mitigate these issues, municipal emergency management was implemented, particularly with Calgary Emergency Management Agency (CEMA).

A tactical operational centre was set up with three objectives: 1) Keep our employees and the public safe while maintaining call loads and investigative excellence; 2) Get people home to drastically reduce the number of employees in the workspace, and; 3) Communicate to and educate the public (and employees) on health-related enforcement; it is important to have psychological support for employees. Time is a critical resource in crises as well as fear among public and own officers. Reconciling anguish is different during COVID-19, as it was a silent and invisible threat.

Operations were changed to address the health emergency, beginning with informing leadership and establishment of a continuity plan. Staff were redeployed, inventory was reconciled, and leadership teams defined which areas had first deployment. Significant decisions were made regarding what services were not offered, given budget shortfalls, and large capital investments that had to be made for supplies, masks, plexiglass barriers, and other COVID-19 expenses. Response to reports were adjusted, which resulted in adjustments made to community policing.

Investigations and enforcement were also impacted as a result of COVID-19, especially with the types and number of crimes. Commercial break and enters increased, while residential break and enters decreased due to stay at home orders, as well as an increase in fraud including those who feigned to be health authorities. Mandatory use of masks altered or limited facial recognition, which impacted what technologies could be used. Online and remote working units were established with technology upgrades that fast-tracked support for online interview capability. This online capability allowed warrants, affidavits, and court decisions to be obtained and sworn in.

Technology was impacted in the beginning but has improved in sophistication since March, 2020. New strategies for corporate decision making needs to be devised to streamline continuity plans and incident management. Essential service delivery was not diminished, but having an incident management team stood up is not a viable way of resource management.

\section{Question Period}

Biggest issue with the pandemic is that COVID-19 is invisible and creates a difficult situation to gauge the effect on people suffering from mental health 
illnesses. We have also seen an uptick in misinformation rhetoric, and the responsibility to provide correct information falls on law enforcement.

\section{KEY POINTS OF DISCUSSION}

\section{Presentation}

- COVID-19 is unlike other public emergencies as it does not seem to have a definitive end.

- Reconciling anguish during COVID-19 is difficult as it is an invisible and silent threat.

- Continuity plans and emergency incident management teams are critical in maintaining service.

- Technology had to be adapted to new COVID-19 conditions.

- Budget shortfalls problematic for maintaining services.

\section{Question Period}

- COVID-19 made it difficult to gauge the effect on people suffering from mental health illnesses.

- Since the COVID-19 lockdown, misinformation rhetoric has increased.

- Responsibility to provide correct information falls on law enforcement.

\section{(c) (i) $\ominus$ \\ EY No ND This work is licensed under a Creative Commons Attribution- NonCommercial-NoDerivatives 4.0 International License.}

(C) (Asif Rashid, 2021)

Published by the Journal of Intelligence, Conflict, and Warfare and Simon Fraser University

Available from: https://jicw.org/ 